\title{
Diversidade genética molecular de progênies de dendezeiro
}

\author{
Crystianne Bentes Barbosa Ferreira(1), Maria Teresa Gomes Lopes ${ }^{(1)}$, Ricardo Lopes ${ }^{(2)}$, \\ Raimundo Nonato Vieira da Cunha( ${ }^{(2)}$, Djair Alves Moreira(3), \\ Willian Silva Barros ${ }^{(4)}$ e Rodrigo Rodrigues Matiello(5)
}

\begin{abstract}
(1)Universidade Federal do Amazonas, Departamento de Produção Animal e Vegetal, Avenida General Rodrigo Otávio Jordão Ramos, no 3.000, Aleixo, CEP60077-000 Manaus, AM. E-mail: crysbarbosa04@yahoo.com.br, mtglopes@ufam.edu.br (2)Embrapa Amazônia Ocidental, AM 010, Km 29, CEP 69048-660 Manaus, AM. E-mail: ricardo.lopes@cpaa.embrapa.br, raimundo.cunha@cpaa.embrapa.br (3)Universidade Federal do Pará, Rua Cel. José Porfírio, no 2.515, São Sebastião, CEP 68371-040 Altamira, PA. E-mail: djair@ufpa.br ${ }^{(4)}$ Universidade Federal de Pelotas, Campus Capão do Leão, s/nº, CEP 96001-970 Capão do Leão, RS. E-mail: wsbarros@hotmail.com ${ }^{(5)}$ Universidade Estadual de Ponta Grossa, Departamento de Fitotecnia e Fitossanidade, Avenida Carlos Cavalcanti, ㄲo 4.748, Uvaranas, CEP 84030-900 Ponta Grossa, PR. E-mail: rrmatiel@uepg.br
\end{abstract}

Resumo - O objetivo deste trabalho foi avaliar a diversidade genética, entre e dentro de progênies de dendezeiro tipo dura, de origem Deli. A caracterização genética foi feita com uso de marcadores microssatélites em 24 progênies usadas na produção comercial de sementes, sendo 22 provenientes de autofecundação e duas de cruzamentos entre irmãos completos. Foi realizada análise de variância molecular entre e dentro das progênies, com posterior construção de um dendrograma. Observou-se baixa variabilidade genética nas progênies, com média de 1,32 alelos por loco e variância genética total igual a 0,3241. A maior parte da variação ocorreu entre progênies. A menor variabilidade genética dentro das progênies pode ser explorada nos cruzamentos com progênies endogâmicas de outras origens, o que facilitaria o alcance de heterose para o desenvolvimento de novas variedades.

Termos para indexação: Elaeis guineensis, avaliação de progênies, heterose, melhoramento genético.

\section{Molecular genetic diversity of oil palm progenies}

\begin{abstract}
The objective of this work was to assess the genetic diversity between and within progenies of dura type oil palm from Deli. Genetic characterization was performed with microsatellite markers on 24 oil palm progenies used in commercial seed production, of which 22 originated from self-fertilization and two from cross-fertilization between full siblings. Molecular analysis of variance was carried out among and within progenies, and a dendrogram was constructed. Low genetic variability was observed within progenies, with an average of 1.32 alleles per locus and total variance of 0.3241 . Most of the variation was found between progenies. The lower genetic variability within progenies can be explored in crossings with endogamic progenies from other origins, which would facilitate heterosis in order to develop new varieties.
\end{abstract}

Index terms: Elaeis guineensis, progeny evaluation, heterosis, genetic improvement.

\section{Introdução}

O dendezeiro (Elaeis guineensis Jacq.) é uma palmeira originária da Costa Ocidental da África (Golfo da Guiné) (Hartley, 1988) e é a principal fonte mundial de óleo vegetal. Em 2006/2007, a produção de óleo de dendê representou $34,7 \%$ da produção mundial de óleos vegetais, e a sua área de plantio foi de $4,8 \%$ do total cultivado com oleaginosas, enquanto o óleo de soja, segunda cultura em ordem de produção, representou $29,8 \%$ da produção total de óleo vegetal, com área de cultivo de $42,5 \%$ da área total de plantio com oleaginosas (Oil World, 2007).

No Brasil, há perspectivas de aumento de plantio de dendezeiro com a criação do Programa de Produção
Sustentável de Palma de Óleo pelo Governo Federal, para diversificação da matriz energética, geração de emprego e de renda. O país dispõe da maior área apta para a expansão do cultivo de dendezeiro no mundo. $\mathrm{O}$ zoneamento agroecológico das áreas desmatadas da Amazônia identificou aproximadamente 30 milhões de hectares aptos para o cultivo da espécie (Ramalho Filho \& Mota, 2010).

Por meio do melhoramento genético, o dendezeiro tem se destacado como principal fonte mundial de óleo vegetal, em virtude de elevados ganhos em produtividade, especialmente após estudo sobre o controle genético monogênico da espessura do endocarpo, na década de 1940 (Beirnaert \& Vanderweyen, 1941). Esses resultados foram determinantes para definição 
do tipo de variedade a ser explorada comercialmente e para o método de melhoramento a ser utilizado no dendezeiro (Meunier \& Gascon, 1972). Existem três tipos de plantas, classificadas segundo a espessura do endocarpo: plantas tipo Dura $(\mathrm{sh}+\mathrm{sh}+)$, que produzem frutos com endocarpo espesso; Pisífera (sh-sh-), com frutos sem endocarpo e, geralmente, abortivos; e Tenera $(\mathrm{sh}+\mathrm{sh}-)$, que apresentam frutos com endocarpo fino e maior proporção de polpa no fruto do que o tipo Dura e são, consequentemente, mais produtivas em óleo.

A seleção recorrente recíproca tem sido utilizada pelos principais programas de melhoramento genético do dendezeiro para explorar a capacidade de combinação entre grupos de origens e características distintas, principalmente na complementação de componentes de produção do cacho. Independentemente das particularidades do método de melhoramento utilizado, as cultivares comerciais são híbridos do tipo Tenera, obtidos do cruzamento entre genitores Dura e Pisífera. Para a obtenção desses genitores, populações Dura e Tenera/Pisífera devem passar por sucessivos ciclos de seleção, recombinação e testes de progênies para capacidade de combinação.

Desde 1960, os programas de melhoramento têm diversificado muito pouco a base genética para produção de sementes comerciais de dendezeiro, sobretudo dos genitores Dura (Cochard et al., 2009). Esses genitores são quase exclusivamente pertencentes à população denominada Dura Deli, que têm origem em apenas quatro plantas oriundas da África, introduzidas em um jardim botânico da Indonésia em 1848 (Maizura et al., 2006). Apesar da existência de variabilidade genética em bancos de germoplasma de dendezeiro, são necessários estudos que orientem a estratégia de utilização dos recursos genéticos disponíveis.

A Empresa Brasileira de Pesquisa Agropecuária é responsável pelo único programa de melhoramento genético de dendezeiro do Brasil. Nesse programa, as cultivares são obtidas a partir de cruzamentos de populações de origem Dura Deli com Pisíferas La Mé. É necessário analisar a diversidade genética das progênies de dendezeiro tipo Dura, de origem Deli, que têm base genética estreita e são utilizadas como fonte exclusiva de genitores Dura das cultivares produzidas atualmente, para orientar sua diversificação no programa de melhoramento. Nesse sentido, marcadores moleculares podem ser usados no estudo da diversidade genética de germoplasma, selvagem ou melhorado, o que pode dar suporte à conservação e ao melhor uso no programa de melhoramento da espécie (Hayati et al., 2004; Maizura et al., 2006; Bakoume et al., 2007; Cochard et al., 2009; Vieira et al., 2009).

A diversidade genética, entre e dentro de progênies, é importante para um programa de seleção recorrente recíproca de dendezeiro, pois permite buscar, nos cruzamentos, a heterose necessária para $\mathrm{o}$ desenvolvimento de variedades.

O objetivo deste trabalho foi avaliar a diversidade genética entre e dentro de progênies de dendezeiro tipo Dura, de origem Deli, usadas na produção comercial de sementes.

\section{Material e Métodos}

Foram analisadas 24 progênies de dendezeiro do tipo Dura, de origem Deli, cada uma com 17 indivíduos, o que totalizou 408 indivíduos. As progênies eram oriundas do programa de seleção recorrente recíproca de dendezeiro da Embrapa, em parceria com o Centro de Cooperação Internacional em Pesquisa Agronômica para o Desenvolvimento (Cirad), na França, e foram utilizadas na produção de sementes de sete cultivares comerciais do tipo Tenera, registradas no Serviço Nacional de Cultivares. As progênies foram mantidas no Campo Experimental do Rio Urubu, da Embrapa Amazônia Ocidental, localizado no Município de Rio Preto da Eva, AM (2 $25^{\prime} 54^{\prime \prime S}$ e $59^{\circ} 33^{\prime} 49^{\prime \prime} \mathrm{W}$, a $59 \mathrm{~m}$ de altitude). O clima da região é do tipo Ami, conforme a classificação de Köppen. As progênies obtidas por autofecundação ou por cruzamentos de irmãos completos foram selecionadas a partir de testes de progênies do programa de seleção recorrente recíproca (Tabela 1) do Cirad, delineado em 1960.

Para extração do DNA das plantas, foi utilizado o método do brometo de cetiltrimetilamônio (CTAB), descrito por Murray \& Thompson (1980), com folhas jovens (primeira folha). Inicialmente, foram testados 21 pares de iniciadores microssatélites (Billotte et al., 2001) em 20 indivíduos, tendo-se amostrado aleatoriamente um indivíduo de cada uma das 20 primeiras progênies (Tabela 1). Os oito locos de marcadores microssatélites (SSR) que apresentaram os melhores resultados de amplificação - mEgCIR0008, mEgCIR0219, mEgCIR0254, mEgCIR1772, mEgCIR0067, mEgCIR0230, mEgCIR0326 e mEgCIR0009) -, em qualidade de leitura e quantidade de polimorfismo, foram analisados nas progênies. 
As amplificações dos microssatélites foram conduzidas em termociclador Mastercycler Gradient, (Eppendorf, Hamburg, Alemanha), tendo-se utilizado as reações e os programas descritos por Billotte et al. (2001).

Os produtos obtidos nas amplificações foram diluídos em proporção de $10 \%$, para uso na genotipagem. Os produtos gerados pela reação em cadeia da polimerase (PCR) foram visualizados em sequenciador automático MegaBace 1000, (GE Healthcare UK Ltd., Buckinghamshire, Inglaterra). A estimativa do tamanho dos alelos (pares de bases) foi realizada com uso do programa Fragment Profiler (GE Healthcare UK Ltd., Buckinhamshire, Inglaterra), com auxílio de marcador de peso molecular Size Standard ET-400-ROX, (GE Healthcare UK Ltd., Buckinghamshire, Inglaterra).

Foram estimados os parâmetros que medem a diversidade genética, como: número total de alelos por progênie, tendo-se considerado todos os locos (A); número médio de alelos por loco $\left(\mathrm{n}_{\mathrm{a}}\right)$; heterozigosidade média, observada (Ho) e esperada $(\mathrm{He})$; diversidade genética total (Ht); índice de fixação intrapopulacional, ou coeficiente de endogamia (Fis); diversidade entre as progênies (Dst); e percentagem de locos polimórficos.

A variância molecular entre e dentro das progênies foi realizada por meio de análise de variância molecular (AMOVA) (Excoffier et al., 1992). O teste de significância para a estimativa da AMOVA foi realizado com base em bootstrap, tendo-se considerado 10.000 reamostragens. Foram calculadas as distâncias genéticas entre as progênies com base no método de Nei (1978). As distâncias genéticas foram utilizadas para construir o dendrograma, por análise de agrupamentos do tipo "unweighted pair-group method using arithmetic averages" (UPGMA). As análises foram calculadas com uso do programa Genes (Cruz, 2008).

\section{Resultados e Discussão}

As 24 progênies apresentaram média total de 10,5 alelos e 1,3177 alelos por loco. A percentagem de

Tabela 1. Forma de obtenção das progênies, genitores, ascendência dos genitores e estimativas de parâmetros genéticos em 24 progênies de dendezeiro tipo Dura, de origem Deli ${ }^{(1)}$.

\begin{tabular}{|c|c|c|c|c|c|c|c|c|c|c|}
\hline Progênie & Obtenção da progênie & Genitor & Ascendência dos genitores & $\mathrm{N}$ & A & na & $\mathrm{He}$ & Ho & Fis & $\mathrm{P}^{(2)}(\%)$ \\
\hline LM11490 & Autofecundação & LM3053 D & DA 5 D x DA 3 D & 17 & 13 & 1,625 & 0,2048 & 0,1397 & 0,3178 & 62,5 \\
\hline LM11076 & Autofecundação & LM3040 D & DA 5 D x DA 3 D & 17 & 8 & 1,000 & 0,0000 & 0,0000 & 1,0000 & 0,0 \\
\hline LM11592 & Autofecundação & LM3869 D & DA 5 D x DA 3 D & 17 & 11 & 1,375 & 0,0214 & 0,0221 & 0,0303 & 37,5 \\
\hline LM11672 & Autofecundação & LM3621 D & DA 5 D x DA 3 D & 17 & 9 & 1,125 & 0,0710 & 0,0074 & 0,0303 & 12,5 \\
\hline LM11547 & Autofecundação & LM3619 D & DA 5 D x DA 3 D & 17 & 12 & 1,500 & 0,1455 & 0,1103 & 0,2422 & 50,0 \\
\hline LM11574 & Autofecundação & LM3606 D & DA 5 D x DA 3 D & 17 & 8 & 1,000 & 0,0000 & 0,0000 & 1,0000 & 0,0 \\
\hline LM11732 & Autofecundação & LM3050 D & DA 5 D x DA 3 D & 17 & 10 & 1,250 & 0,0277 & 0,0000 & 1,0000 & 25,0 \\
\hline LM12236 & Autofecundação & LM3037 D & DA 5 D x DA 3 D & 17 & 10 & 1,250 & 0,0277 & 0,0000 & 1,0000 & 25,0 \\
\hline LM13533 & Autofecundação & LM3257 D & DA 5 D x DA 3 D & 17 & 8 & 1,000 & 0,0000 & 0,0000 & 1,0000 & 0,0 \\
\hline LM14376 & Autofecundação & LM3038 D & DA 5 D x DA 3 D & 17 & 8 & 1,000 & 0,0000 & 0,0000 & 1,0000 & 0,0 \\
\hline LM12213 & $\mathrm{CIC}$ & LM3869 D x LM3040 D & DA 5 D x DA 3 D & 17 & 13 & 1,625 & 0,1477 & 0,1397 & 0,0542 & 62,5 \\
\hline LM12119 & $\mathrm{CIC}$ & LM3043 D x LM3038 D & DA 5 D x DA 3 D & 17 & 12 & 1,500 & 0,2158 & 0,0735 & 0,6593 & 50,0 \\
\hline LM11310 & Autofecundação & LM3604 D & DA 5 D X DA 3 D & 17 & 10 & 1,250 & 0,1142 & 0,1765 & 0,5455 & 25,0 \\
\hline LM12366 & Autofecundação & LM4976 D & DA 115 D x LM 269 D & 17 & 11 & 1,375 & 0,1282 & 0,1544 & 0,2040 & 37,5 \\
\hline LM12221 & Autofecundação & LM5215 D & DA 115 D x LM 269 D & 17 & 12 & 1,500 & 0,1404 & 0,0074 & 0,9476 & 50,0 \\
\hline LM12280 & Autofecundação & LM5100 D & DA 115 D x LM 269 D & 17 & 8 & 1,000 & 0,0000 & 0,0000 & 1,0000 & 0,0 \\
\hline LM12217 & Autofecundação & LM5229 D & DA 115 D x LM 269 D & 17 & 10 & 1,250 & 0,0519 & 0,0000 & 1,0000 & 25,0 \\
\hline DA3091 & Autofecundação & DA115 D & DA 115 D x LM 269 D & 17 & 15 & 1,875 & 0,1942 & 0,0882 & 0,5457 & 87,5 \\
\hline LM12509 & Autofecundação & LM4968 D & DA 115 D x LM 269 D & 17 & 12 & 1,500 & 0,1049 & 0,0956 & 0,0887 & 50,0 \\
\hline LM12826 & Autofecundação & LM5799 D & DA 8 D x DA 115 D & 17 & 12 & 1,500 & 0,1066 & 0,0074 & 0,9310 & 50,0 \\
\hline LM13246 & Autofecundação & LM2940 D & LM 404 D x DA 10 D & 17 & 11 & 1,375 & 0,1386 & 0,0662 & 0,5226 & 37,5 \\
\hline LM13375 & Autofecundação & LM3468 D & LM 404 D x DA 10 D & 17 & 8 & 1,000 & 0,0000 & 0,0000 & 1,0000 & 0,0 \\
\hline LM11591 & Autofecundação & LM2935 D & LM 404 D x DA 10 D & 17 & 14 & 1,750 & 0,2156 & 0,0515 & 0,7613 & 75,0 \\
\hline PO3572 & Autofecundação & PO1994 D & LM 404 D x DA 3 D & 17 & 8 & 1,000 & 0,0000 & 0,0000 & 1,0000 & 0,0 \\
\hline Média & - & - & - & 17 & 10,5 & 1,3177 & 0,0857 & 0,0475 & 0,6617 & 29,9 \\
\hline
\end{tabular}

(1) N, número de indivíduos amostrados; A, número total de alelos; na, número médio de alelos por loco; He, heterozigosidade esperada sob equilíbrio de Hardy-Weinberg; Ho, heterozigosidade observada; Fis, coeficiente de endogamia; e P, percentagem de locos polimórficos. ${ }^{(2)}$ Para o cálculo, foram considerados como polimórficos os locos em que o alelo mais comum tem frequência menor que $95 \%$. CIC, cruzamento de irmãos completos 
polimorfismo variou de 12,5 a $87,5 \%$, em 17 progênies, mas não foi observado polimorfismo nas outras sete (Tabela 1). Os níveis de variação alélica foram relativamente baixos, uma vez que as progênies tiveram ascendência em apenas sete plantas e passaram por seleção durante a condução do programa de melhoramento. Espera-se que a seleção leve à fixação de muitos alelos, mesmo dos que não estão diretamente sob seleção.

As progênies LM11076, LM11574, LM13533, LM14376, LM12280, LM13375 e PO3572 (Tabela 1) apresentaram-se monomórficas em todos os locos avaliados e, portanto, foram agrupadas em um único grupo no dendrograma (Figura 1). Essas progênies podem ser consideradas fixadas para estes locos. Quando um loco apresenta um alelo fixado, nenhum outro alelo está presente na população, que também é tida como fixada para este mesmo loco.
Dois alelos, que apresentam frequência entre 0,350 e 0,650 , foram considerados similares (Frankel et al., 1996). Ao se analisar a similaridade entre as frequências alélicas das 17 progênies polimórficas, pôde-se observar que LM11076, LM11574, LM14376, LM12213, LM11310, LM12217, DA3091, LM12119 e LM12509 apresentaram equidade gênica entre os alelos no loco mEgCIR0219. As progênies LM12236, LM13533, DA3091, LM12509 e LM12826, para o loco mEgCIR0230, e as progênies LM11490, LM12213 e LM12221, para o loco mEgCIR0326, também apresentaram equidade gênica entre os alelos. Nos locos mEgCIR0008, mEgCIR0254, mEgCIR1772, mEgCIR0067 e mEgCIR0009, nenhuma progênie apresentou equidade gênica entre os alelos. A ausência de equidade gênica, segundo Frankel et al. (1996), pode indicar menor diversidade nas populações e evidenciar maior suscetibilidade à fixação e à perda de alelos,

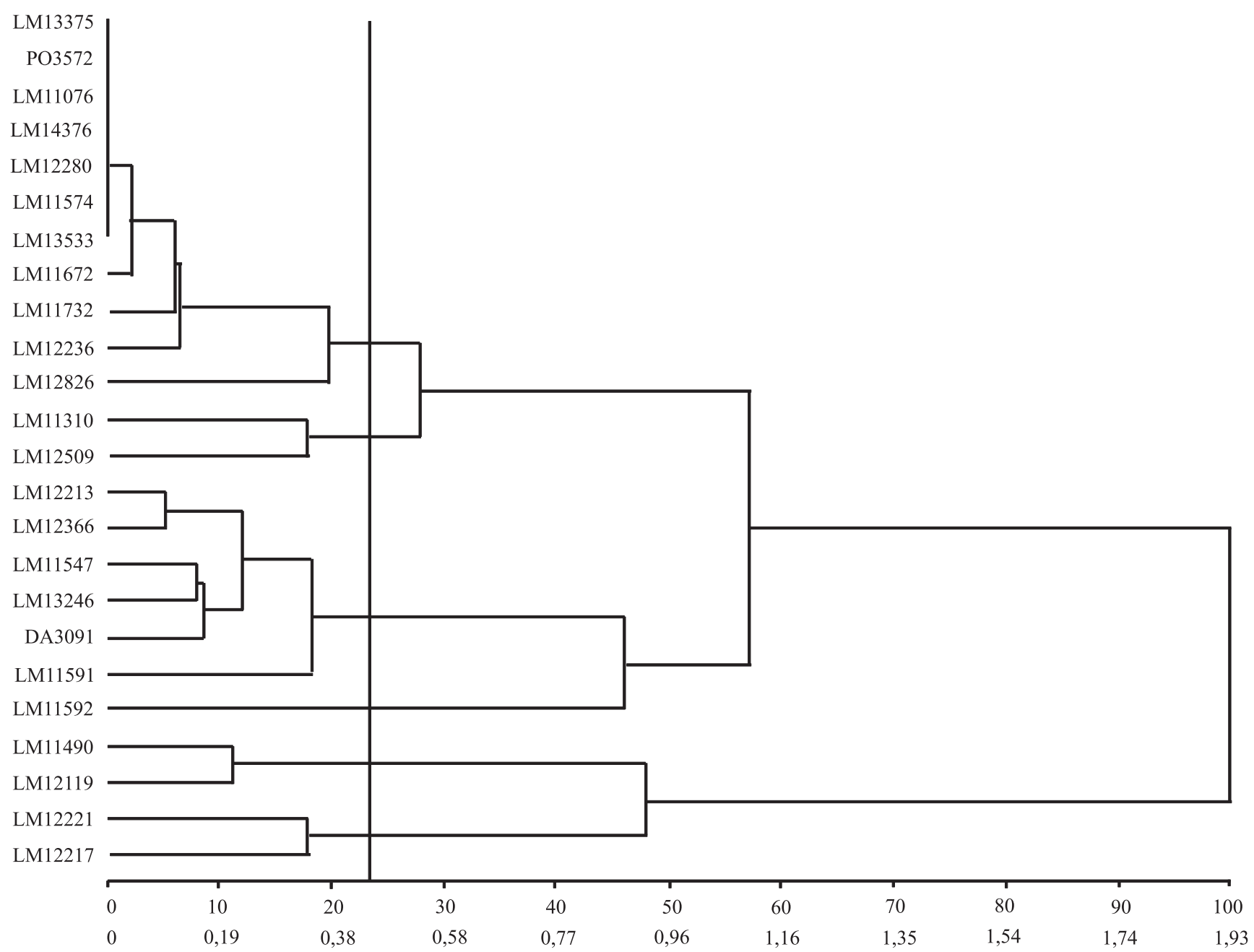

Figura 1. Dendrograma das progênies endogâmicas de dendezeiro, calculado de acordo com a identidade genética de Nei. 
quando as populações são submetidas a perturbações e a gargalos genéticos. Assim, as progênies avaliadas estão sujeitas aos efeitos de deriva genética, pois apresentam alelos que podem ser perdidos por seleção.

No conjunto das 24 progênies, a heterozigosidade observada (Ho), que é a proporção de indivíduos heterozigotos nas amostras da população, variou de 0,0074, nas progênies LM11672, LM12221 e LM12826, a 0,1765, na progênie LM11310, com média de 0,0475 (Tabela 1). Já a heterozigosidade esperada (He), que é a probabilidade de um indivíduo ser heterozigoto em um loco qualquer, foi maior que a observada. Portanto, ficou caracterizada a presença de excesso de homozigotos. O aumento de homozigotos indica a existência de um processo endogâmico (Borém \& Miranda, 2009). Como o dendezeiro é planta alógama e as progênies são geneticamente aparentadas, é de se esperar que os efeitos da endogamia interfiram diretamente nos índices de heterozigosidade, o que contribui para a homogeneidade dentro das progênies. $\mathrm{O}$ coeficiente médio de endogamia das progênies $($ Fis $=0,6617)$ apresentou variação de 0,0303 a 1,0.

A heterozigosidade pode ser considerada como um indicativo da existência de variabilidade genética para espécies alógamas, como o dendezeiro. As baixas percentagens de locos polimórficos, commédia de $29,9 \%$, podem ser atribuídas à alta homozigose encontrada nas progênies.

A diversidade genética total $(\mathrm{Ht})$ atingiu média de 0,1829 (18,29\%) (Tabela 2), o que indica baixa diversidade genética do material avaliado neste trabalho, ao contrário do observado por Allou et al. (2008), com quatro locos microssatélites. De acordo com esses autores, há maior variância genética dentro de cada grupo de dendezeiro do que entre os dois

Tabela 2. Diversidade genética total (Ht), diversidade dentro das progênies (Hs) e diversidade entre as progênies (Dst) de dendezeiro tipo Dura, de origem Deli, tendo-se utilizado oito locos SSR.

\begin{tabular}{lccc}
\hline Loco & $\mathrm{Ht}$ & $\mathrm{Hs}$ & Dst \\
\hline mEgCIR0008 & 0,0097 & 0,0108 & 0,1100 \\
mEgCIR0219 & 0,4367 & 0,2201 & 0,4960 \\
mEgCIR0254 & 0,0032 & 0,0016 & 0,4992 \\
mEgCIR1772 & 0,2714 & 0,0889 & 0,6724 \\
mEgCIR0067 & 0,2680 & 0,0888 & 0,6689 \\
mEgCIR0230 & 0,0218 & 0,0225 & 0,3500 \\
mEgCIR0326 & 0,4323 & 0,2252 & 0,4791 \\
mEgCIR0009 & 0,0201 & 0,0179 & 0,1086 \\
\hline Média & 0,1829 & 0,0845 & 0,5381 \\
\hline
\end{tabular}

grupos avaliados. Resultados contrastantes também foram observados por Cole et al. (2007), com três locos microssatélites, e por Couvreur et al. (2006), com oito locos, ao avaliar populações de pupunheira (Bactris gasipaes Kunth). Esses trabalhos mostram o comportamento geral das populações de espécies alógamas.

A maior diversidade observada esteve concentrada entre as progênies (Dst), com valor médio de 0,5381, e o valor da diversidade dentro das progênies (Hs) foi, em média, de 0,0845 (Tabela 2). Furlan et al. (2007), ao utilizar microssatélites em população melhorada de Pinus caribaea Morelet, também relataram maior diversidade genética entre progênies.

A AMOVA indicou diferença significativa entre as progênies $(0,1981 ; p \leq 0,0001)$, tendo retido $61,13 \%$ da variação total e, consequentemente, alto nível de diferenciação genética (Tabela 3). Já a variância molecular existente dentro das 24 progênies, foi de $38,87 \%$ da variação total. A existência de variância genética dentro de progênies indica a capacidade de preservação de variabilidade genética, que pode ser explorada no melhoramento por seleção. Cedillo et al. (2008) também verificaram a existência de variabilidade genética em caracteres fenotípicos dentro de progênies de irmãos completos de dendezeiro tipo Dura, para o melhoramento da espécie.

Em plantas alógamas, seja em populações naturais ou em coleções de germoplasma, a maior variabilidade tem sido observada dentro das populações/procedências. No entanto, no presente trabalho, verificou-se que a maior parte da variação ocorreu entre as progênies, o que era de se esperar, pois $91,67 \%$ destas foram oriundas de autofecundação.

A população Dura Deli apresenta excelente desempenho agronômico, o que pode ser atribuído ao sucesso no processo de seleção massal ao qual foi submetida. Este pode ser considerado um exemplo eficiente de pré-melhoramento (Cochard et al., 2009); por isso, seu uso predomina quase que exclusivamente nos principais programas de melhoramento genético

Tabela 3. Análise de variância molecular obtida das 24 progênies de dendezeiro tipo Dura, de origem Deli, tendo-se utilizado oito locos SSR.

\begin{tabular}{lcccc}
\hline Fonte de variação & Variância & Variação (\%) & 1-Dst & $\mathrm{p}$ \\
\hline Entre & 0,1981 & 61,13 & 0,3887 & 0,0001 \\
Dentro & 0,1260 & 38,87 & & \\
\hline Total & 0,3241 & 100 & & \\
\hline
\end{tabular}


do dendezeiro. Os quatro ou cinco ciclos de seleção massal, aos quais foi submetida essa população, contribuíram para eliminar alelos indesejados (Cochard et al., 2009). Contudo, o forte efeito fundador, causado pelo uso de poucas (quatro) plantas fundadoras, e as sucessivas gerações de autofecundação ou cruzamentos entre irmãos, seguidos de deriva genética, resultaram em drástica redução da variabilidade genética dessa população. Portanto, a diversificação da população Dura Deli é importante, pois, conforme evidenciado, ela apresenta baixa diversidade alélica e baixa heterozigozidade, o que pode levar a maior suscetibilidade a fatores bióticos ou abióticos.

No entanto, para que se tenha progresso com essa diversificação, é necessário explorar e manter a excelente capacidade de combinação do grupo Dura Deli, caracterizado pela produção de pequeno número de cachos grandes e considerado como fonte dos genitores femininos, com o La Mé, caracterizado pela produção de grande número de cachos pequenos e tido como fonte dos genitores masculinos, o que tem garantido o sucesso do programa de seleção recorrente recíproca que deu origem às atuais cultivares híbridas do tipo Tenera (Dura x Pisífera) produzidas pela Embrapa. A análise da estrutura genética das populações de dendezeiro realizada por Cochard et al. (2009) indica a necessidade de explorar cruzamentos Dura Deli com as origens Brasil, Benin, Nigéria e outras da África Central, para a formação de novas populações Dura que mantenham a capacidade de combinação com a população La Mé, para manter a excelente capacidade de combinação das origens Deli x La Mé.

O dendrograma mostra o agrupamento das progênies de dendezeiro avaliadas em seis grupos, o que pode auxiliar na orientação de novos cruzamentos. As progênies localizadas no mesmo grupo podem ser representadas por apenas uma, em novos cruzamentos com progênies de outras origens, dependendo da disponibilidade de recursos do programa para o planejamento de novos experimentos quanto à capacidade de combinação.

\section{Conclusões}

1. A menor variabilidade genética dentro das progênies avaliadas pode ser explorada nos cruzamentos com progênies endogâmicas de outras origens, o que facilitaria o alcance da heterose para o desenvolvimento de variedades.
2. Os marcadores SSR, ao detectarem informações de polimorfismos, são eficazes na quantificação da diversidade genética dentro e entre as progênies de dendezeiro e facilitam a orientação dos cruzamentos.

3. Para ampliar a base genética do programa de melhoramento, as progênies Dura, de origem Deli, devem ser exploradas em cruzamentos com outras origens Dura, que mantenham a boa capacidade de combinação com a população de origem La Mé, para garantir os ganhos de produtividade que vêm sendo alcançados com a combinação Deli x La Mé, nos programas de seleção recorrente recíproca.

\section{Agradecimentos}

À Financiadora de Estudos e Projetos, à Fundação de Amparo à Pesquisa do Estado do Amazonas e ao Conselho Nacional de Desenvolvimento Científico e Tecnológico, pelo apoio financeiro.

\section{Referências}

ALLOU, D.; ADON, B.; SANGARE, A. Molecular variability from two selection of BRT10 population in an inbreeding program of oil palm (Elaeis guineensis Jacq.) in Côte d'Ivoire. African Journal of Biotechnology, v.7, p.3550-3553, 2008.

BAKOUME, C.; WICKNESWARI, R.; RAJANAIDU, N.; KUSHAIRI, A.; AMBLARD, P.; BILLOTTE, N. Allelic diversity of natural oil palm (Elaeis guineensis Jacq.) populations detected by microsatellite markers: implications for conservation. Plant Genetic Resources: Characterization and Utilization, v.5, p.104-107, 2007.

BEIRNAERT, A.; VANDERWEYEN, R. Contribution a l'étude génétique et biométrique des variétés d'Elaeis guineensis Jacquin. Gembloux: Institut National pour Etude Agronomique du Congo Belge, 1941. 101p. (INEAC. Serie scientifique, 27).

BILLOTTE, N.; RISTERUCCI, A.M.; NOYER, J.L.; AMBLARD, P.; BAURENS, F.C. Development, characterisation, and across-taxa utility of oil palm (Elaeis guineensis Jacq.) microsatellite markers. Genome, v.44, p.413-425, 2001.

BORÉM, A.; MIRANDA, G.V. Melhoramento de plantas. Viçosa: UFV, 2009. 529p.

BOTSTEIN, D.; WHITE, R.L.; SKOLNICH, M.; DAVIS, R.W. Construction of a genetic linkage map in man using restriction fragment length polymorphisms. American Journal of Human Genetics, v.32, p.314-331, 1980.

CEDILLO, D.S.O.; FERREIRA, F.M.; BARROS, W.B.; CRUZ, C.D.; DIAS, L.A. dos S. ROCHA, R. Selection among and within and combined selection in oil palm families derived from Dura $\mathrm{x}$ Dura. Ciência Rural, v.38, p.65-71, 2008.

COCHARD, B.; ADON, B.; REKIMA, S.; BILLOTTE, N.; CHENON, R.D.; KOUTOU, A.; NOUY, B.; OMORÉ, A.; PURBA, 
A.R.; GLAZSMAN, J.C. Geographic and genetic structure of African oil palm diversity suggests new approaches to breeding. Tree Genetics and Genomes, v.5, p.493-504, 2009.

COLE, D.M; WHITE, T.L.; NAIR, P.K.R. Maintaining genetic resources of peach palm (Bactris gasipaes Kunth): the role of seed migration and swidden-fallow management in northeastern Peru. Genetic Resources and Crop Evolution, v.54, p.189-204, 2007.

COUVREUR, T.L.P.; BILLOTTE, N.; RISTERUCCI, A.M.; LARA, C.; VIGOUROUX, Y.; LUDEÑA, B.; PHAM, J.L.; PINTAUD, J.C. Close genetic proximity between cultivated and wild Bactris gasipaes revealed by microsatellite markers in Western Ecuador. Genetic Resources and Crop Evolution, v.53, p.1361-1373, 2006.

CRUZ, C.D. Programa Genes. Viçosa: UFV, 2008. 278p.

EXCOFFIER, L.; SMOUSE, P.E.; QUATTRO, J.M. Analysis of molecular variant inferred from metric distances among DNA haplotypes: application to human mitochondrial DNA restriction data. Genetics, v.131, p.479-491, 1992.

FRANKEL, O.H.; BROWN, A.H.D.; BURDON, J.J. The conservation of plant biodiversity. Cambridge: Cambridge University, 1996. 299p.

FURLAN, R.A.; MORI, E.S.; TAMBARUSSI, E.V.; MORAES, C.B.; JESUS, F.A.; ZIMBACK, L. Estrutura genética de populações de melhoramento de Pinus caribaea var. hondurensis por meio de marcadores microssatélites. Bragantia, v.66, p.553-563, 2007.

HARTLEY, C.S.W. The oil palm. London: Longman. 1988. $761 \mathrm{p}$.
HAYATI, A.; WICKNESWARI, R.; MAIZURA, I.; RAJANAIDU, N. Genetic diversity of oil palm (Elaeis guineensis Jacq.) germplasm collections from Africa: implications for improvement and conservation of genetic resources. Theoretical and Applied Genetics, v.108, p.1274-1284, 2004.

MAIZURA, I.; RAJANAIDU, N.; ZAKRI, A.H.; CHEAH, S.C. Assessment of genetic diversity in oil palm (Elaeis guineensis Jacq.) using restriction fragment length polymorphism (RFLP). Genetic Resources and Crop Evolution, v.53, p.187-195, 2006.

MEUNIER, J.; GASCON, J.P. Le schéma général d'amélioration du palmier à huile à l'I.R.H.O. Oleagineux, v.27, p.1-12, 1972.

MURRAY, M.G.; THOMPSON, W.F. Rapid isolation of high molecular weight plant DNA. Nucleic Acids Research, v.8, p.1134-1137, 1980.

NEI, M. Estimation of average heterozygosity and genetic distance from a small number of individuals. Genetics, v.89, p.583-590, 1978.

OIL WORLD. Oil World Annual. Hamburg: ISTA Mielke, 2007.

RAMALHO FILHO, A; MOTA, P.E.F. da (Coord.). Zoneamento agroecológico do dendezeiro para as áreas desmatadas da Amazônia Legal: relatório do ano de 2010. Rio de Janeiro: Embrapa Solos, 2010. 44p.

VIEIRA, E.S.N.; SCHUSTER, I.; SILVA, R.B. da; OLIVEIRA, M.A.R. de. Variabilidade genética em cultivares de soja determinada com marcadores microssatélites em gel de agarose. Pesquisa Agropecuária Brasileira, v.44, p.1460-1466, 2009.

Recebido em 11 de outubro de 2011 e aprovado em 24 de fevereiro de 2012 